Radiation Effects in Nuclear Waste Materials

(Project Number: 73750)

\author{
Principal Investigator \\ William J. Weber \\ Pacific Northwest National Laboratory \\ P.O. Box 999, MSIN K8-93 \\ Richland, WA 99352 \\ (509) 376-3644 \\ bill.weber@pnl.gov
}

\title{
Co-Investigators
}

Lumin Wang

Nuclear Engineering \& Radiological Sciences

The University of Michigan

2355 Bonisteel Boulevard

Ann Arbor,MI 48109-2104

(734) 647-8530

lmwang@umich.edu

Nancy J. Hess

Pacific Northwest National Laboratory

P.O. Box 999, MSIN P7-50

Richland, WA 99352

(509) 376-9808

nancy.hess@pnl.gov

Jonathan P. Icenhower

Pacific Northwest National Laboratory

P.O. Box 999, MSIN K6-81

Richland, WA 99352

(509) 372-0078

jonathan.icenhower@pnl.gov

Suntharampillai (Theva) Thevuthasan

Pacific Northwest National Laboratory

P.O. Box 999, MSIN K8-93

Richland, WA 99352

(509) 376-1375

theva@pnl.gov

Graduate Students: None 


\section{Research Objective}

The objective of this project is to develop a fundamental understanding of radiation effects in glasses and ceramics, as well as the influence of solid-state radiation effects on aqueous dissolution kinetics, which may impact the performance of nuclear waste forms and stabilized nuclear materials. This work provides the underpinning science to develop improved glass and ceramic waste forms for the immobilization and disposition of high-level tank waste, excess plutonium, plutonium residues and scrap, other actinides, and other nuclear waste streams. Furthermore, this work is developing develop predictive models for the performance of nuclear waste forms and stabilized nuclear materials. Thus, the research performed under this project has significant implications for the immobilization of High-Level Waste (HLW) and Nuclear Materials, two mission areas within the Office of Environmental Management (EM). With regard to the HLW mission, this research will lead to improved understanding of radiation-induced degradation mechanisms and their effects on dissolution kinetics, as well as development of predictive models for waste form performance. In the Nuclear Materials mission, this research will lead to improvements in the understanding of radiation effects on the chemical and structural properties of materials for the stabilization and long-term storage of plutonium, highly-enriched uranium, and other actinides. The research uses plutonium incorporation, ion-beam irradiation, and electron-beam irradiation to simulate the effects of alpha decay and beta decay on relevant glasses and ceramics. The research under this project has the potential to result in improved glass and ceramic materials for the stabilization and immobilization of high-level tank waste, plutonium residues and scraps, surplus weapons plutonium, highly-enriched uranium, other actinides, and other radioactive materials.

\section{Research Progress and Implications}

This report summarizes work after 27 months of a 3-year project.

\section{Alpha-Decay Effects in Ceramics}

New capabilities for nuclear magnetic resonance (NMR) and Raman spectroscopy of actinidecontaining compounds have been recently developed at Pacific Northwest National Laboratory (PNNL) under separate funding. The Pu-containing zircon samples, which were studied in detail under the first 3-year period of this project, provide a unique opportunity to test these new facilities and answer some very relevant and controversial scientific issues that have since developed. As part of this effort, a collaborative arrangement has been established with Dr. Ian Farnan (Cambridge University, UK), who has conducted the most extensive NMR studies of radiation effects in natural zircons, in order to utilize his expertise in NMR studies of the $\mathrm{Pu}$ zircons at PNNL. As part of this collaboration, a double-containment NMR capsule has been designed and constructed by Ian Farnan at Cambridge University. Preliminary testing of this capsule was conducted in early April 2003 at PNNL using the actinide NMR facility, and the actually NMR studies of the Pu-containing zircons are planned for August 2003, along with complementary studies using the new Raman spectroscopy capabilities. 


\section{Alpha-Decay Effects in Glasses}

Three compositionally identical Pu-bearing reference glasses were prepared on July 27, 1982, each containing $1 \mathrm{wt} . \% \mathrm{PuO}_{2}$; however, the ${ }^{238} \mathrm{Pu} /{ }^{239} \mathrm{Pu}$ isotopic ratio was different in each glass. As a result, the alpha-activities (and resulting dose) in the glasses vary by nearly a factor of 200 . A significant amount of effort has been expended on developing the procedures and capabilities to perform a comprehensive set of dissolution studies on these three isotopically different $\mathrm{Pu}$ containing glasses based on the single-pass flow-through (SPFT) test method to measure the forward reaction rate as a function of temperature and $\mathrm{pH}$. The forward rate is the most conservative estimate of the radionuclide release rate from the glasses. These procedures and capabilities have been successfully implemented, and the studies were initiated during the summer of 2002.

Because of the high flow-through rate $(60 \mathrm{~mL} /$ day $)$ used in these tests, the solution in contact with the glass remains very dilute in dissolved glass components, and the buildup of alpharadiolysis products, which can enhance dissolution rates in these glasses, is minimized. Using dilute $\mathrm{pH}$ buffers also controls solution $\mathrm{pH}$. With this test method, it is possible to unambiguously compare the results between glasses with different radiation damage levels and quantitatively assess differences in their dissolution rate. The SPFT experiments have been run over the complete $\mathrm{pH}$ range, from $\mathrm{pH} 2$ to 11 . The reaction mechanisms that control glass dissolution kinetics are different in acidic versus basic solutions. Thus, experiments conducted at different $\mathrm{pH}$ values will allow us to separate and correlate the ingrowth of specific defect structures with well-understood dissolution reaction mechanisms. In addition, the SPFT experiments have been conducted at four different temperatures $\left(20,40,70\right.$, and $\left.90^{\circ} \mathrm{C}\right)$. The purpose is to determine the activation energy controlling the dissolution kinetics. The activation energy in radiation-damaged samples needs to be determined in order that dissolution rates can be calculated as a function of temperature in a storage or repository environment. While the elemental concentrations of most elements were above the detection threshold, the $\mathrm{Pu}$ concentrations were just at the detection threshold and could not be quantified.

The measured normalized elemental release rates as a function of ${ }^{238} \mathrm{Pu}$ concentration are shown in Fig. 1 for experiments conducted at $83^{\circ} \mathrm{C}$ and $\mathrm{pH}\left(25^{\circ} \mathrm{C}\right)=9$. Rates based on release of $\mathrm{Al}, \mathrm{Cs}$, and $\mathrm{Na}$ range between 1 and $2 \mathrm{~g} \mathrm{~m}^{-2} \mathrm{~d}^{-1}$ for the three glass samples. Release rates based on $\mathrm{B}$ and $\mathrm{U}$ are slightly lower $\left(0.5\right.$ to $\left.1 \mathrm{~g} \mathrm{~m}^{-2} \mathrm{~d}^{-1}\right)$ compared with the other elements. This could be associated with a higher local order for these ions, as suggested by prior detailed characterization of the structures. Within experimental error, there is no significant effect of accumulated dose on the forward dissolution rate over the range from $1.2 \times 10^{16}$ to $2.5 \times 10^{18}$ alpha-

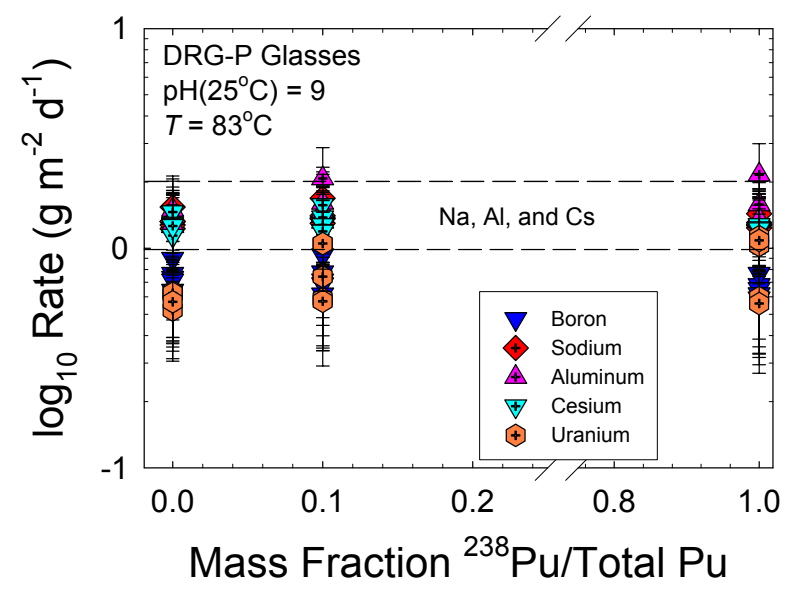

Fig. 1. Normalized log dissolution rate as a function of the mass fraction of ${ }^{238} \mathrm{Pu}$ in the glass. 
decays/g. Thus, the effects of radiation damage on the dissolution rates appear to be negligible. Furthermore, the dissolution rates are not significantly larger than would be expected based on other results for glasses. There is, however, one potential issue that remains. It is well established that the dissolution rates can be strongly influenced by the system energy. As discussed in previous reports, the increase in system energy (i.e., stored energy) for all three glasses, including the lowest dose glass, is rather large compared to the unirradiated state. If there is a threshold in stored energy for enhanced dissolution that is below $100 \mathrm{~J} / \mathrm{g}$, then all three glasses have exceeded it. Thus, it still cannot be conclusively stated that there is no radiation effect; however, this hypothesis can now be easily tested.

To confirm the validity of these results, a final confirmatory series of identical dissolution tests need to be conducted on fully annealed samples of the low activity glass. This glass has considerable stored energy due to defects and broken bonds, but has not yet undergone any significant rearrangement of the glass network (i.e., density change). Annealing this glass at 300 to $350^{\circ} \mathrm{C}$ should readily return it to its initial undamaged state. Dissolution measurements of the annealed glass will provide the final conclusive set of results to evaluated the effects, if any, of self-radiation on glass dissolution in these glasses. The results may also provide conclusive understanding of whether the driving force for any radiation-enhanced dissolution in glasses is related to defects and broken bonds (i.e., stored energy) or to network rearrangement (i.e., density changes). This would be of great scientific and technological importance in the development of predictive models. This work is proposed as part of a renewal proposal.

\section{Simulation of Radiation Effects Using Ion Beams}

The $\mathrm{Gd}_{2}\left(\mathrm{Ti}_{1-\mathrm{y}} \mathrm{Zr}_{\mathrm{y}}\right)_{2} \mathrm{O}_{7}$ pyrochlore series undergoes a structural phase transition from pyrochlore structure $(\mathrm{Fd} \overline{3} \mathrm{~m})$ to defect fluorite structure $(\mathrm{Fm} \overline{3} \mathrm{~m})$ that can be compositionally driven by increasing $\mathrm{Zr}$ content or thermally driven by sintering $\mathrm{Zr}$-rich compositions at temperatures above $1550^{\circ} \mathrm{C}$. Recent results demonstrate that ion-beam irradiation can also drive the structural phase transition for Zr-rich compositions. In an effort to understand the effects of irradiation and composition on this phase transition powder, X-ray diffraction, polarized Raman, reflection infrared, and X-ray absorption spectroscopy experiments were conducted on $\mathrm{Gd}_{2}\left(\mathrm{Ti}_{1-\mathrm{y}} \mathrm{Zr}_{\mathrm{y}}\right)_{2} \mathrm{O}_{7}$ pyrochlores prior to and following irradiation with $2 \mathrm{MeV} \mathrm{Au}{ }^{2+}$ ions to an ion fluence of 5 ions $/ \mathrm{nm}^{2}$. Analysis of the vibrational and X-ray absorption data suggests that the structural integrity of the pyrochlore structure is based on distorted corner-shared $\mathrm{TiO}_{6}$ and $\mathrm{ZrO}_{6}$ octahedra. The vibrational spectra indictate that both anion and cation disorder precede the compositionallydriven phase transition; however, cation disorder appears to dominate the irradiation-driven transition. Analyses of the extended X-ray absorption fine structure of the Ti and Zr K-edges, along with the $\mathrm{Gd} \mathrm{L}_{\mathrm{III}}$-edges, indicate a significant change in the Gd local environment upon irradiation and with increasing $\mathrm{Zr}$ content. The Ti and $\mathrm{Zr}$ local environments are less affected by irradiation or compositional change but show evidence of increasing disorder that can be attributed to rotations about shared polyhedral edges and corners. Thus, the radiation-driven transition appears to be dominated by cation disorder and interpolyhedral rotations along edges and corners.

Near-edge x-ray absorption fine structure spectroscopy (NEXAFS) and x-ray photoelectron spectroscopy (XPS) measurements have been carried out at the Advanced Light Source on 
unirradiated and irradiated $\left(2.0 \mathrm{MeV} \mathrm{Au}^{2+}, 8 \mathrm{Au}^{2+} / \mathrm{nm}^{2}\right)$ single crystal $\mathrm{Gd}_{2} \mathrm{Ti}_{2} \mathrm{O}_{7}$ and polycrystalline $\mathrm{Gd}_{2}\left(\mathrm{Ti}_{1-\mathrm{x}} \mathrm{Zr}_{\mathrm{x}}\right)_{2} \mathrm{O}_{7}(\mathrm{x}=0,0.25,0.5$, and 1.0). The Ti L-edge NEXAFS for unirradiated $\mathrm{Gd}_{2}\left(\mathrm{Ti}_{1-\mathrm{x}} \mathrm{Zr}_{\mathrm{x}}\right)_{2} \mathrm{O}_{7}$ provides evidence that Ti occupies a distorted octahedral environment as in $\mathrm{TiO}_{2}$ when $\mathrm{x}=0$. Hence, with increasing $\mathrm{x}$, the deviation from the regular octahedral symmetry decreases, and for $\mathrm{x} \geq 0.75$, Ti occupies regular octahedral site as in $\mathrm{SrTiO}_{3}$. The oxygen K-edge NEXAFS for unirradiated $\mathrm{Gd}_{2}\left(\mathrm{Ti}_{1-\mathrm{x}} \mathrm{Zr}_{\mathrm{x}}\right)_{2} \mathrm{O}_{7}$ strongly supports that $\mathrm{Ti}$ is systematically replaced by $\mathrm{Zr}$ with increasing $\mathrm{x}$. In addition, unlike $\mathrm{Ti}$, the coordination number of $\mathrm{Zr}$ increase with increasing $\mathrm{x}$, and for $\mathrm{x} \geq 0.75$, the number of oxygen near-neighbors is eight as in yttria-stablized-ZrO2. The results from the irradiated samples are still undergoing evaluation.

To assess the chemical durability of compositions in this pyrochlore system, SPFT dissolution experiments were performed on monoliths of $\mathrm{Gd}_{2}\left(\mathrm{Ti}_{1-\mathrm{x}} \mathrm{Zr}_{\mathrm{x}}\right)_{2} \mathrm{O}_{7}$ pyrochlores at $\mathrm{pH}=2, \mathrm{~T}=90^{\circ} \mathrm{C}$. The compositions of the specimens studied were $\mathrm{x}=0,0.25,0.50,0.75$, and 1.00 on a molar basis. All of these specimens manifest the pyrochlore structure, except the zirconate end-member $(\mathrm{x}=1.00)$, which displayed the defect fluorite structure (Fm3m space group) due to processing constraints. Steady-state dissolution rates (based on the release of $\mathrm{Gd}$ ) indicate that as $\mathrm{Zr}$ is progressively substituted for $\mathrm{Ti}$ in the pyrochlore lattice, the log of the normalized dissolution rate $\left(\mathrm{g} \mathrm{m}^{-2} \mathrm{~d}^{-1}\right)$ decreases non-linearly from -1.80 at $\mathrm{x}=0$ to -3.90 at $\mathrm{x}=0.75$. Specimens at $\mathrm{x}=$ 1.00 display a relative increase in rate $(-2.20)$ compared to the minimum rate at $x=0.75$. The change in dissolution characteristics is attributed to the relatively stronger $\mathrm{Zr}-\mathrm{O}$ bond compared to Ti-O, and to the relative change in solubility of the materials as disorder becomes more prominent. The analysis of these samples and interpretation of the results are still ongoing, but should be completed by the end of the current fiscal year.

\section{Simulation of Radiation Effects using Electron Beams}

The only method available to timely evaluate the effects of beta decay on the performance of nuclear waste glasses is electron-beam irradiation. This requires the establishment of a suitable and reliable radiation protocol for glasses, similar to that developed for radiation-induced amorphization in ceramics. The work being carried out at the University of Michigan under this project is focused on understanding radiation-damage processes in complex glasses and developing the necessary protocols to perform accelerated radiation effects testing. Much of this work is enabled by the advanced analytical electron microscope (AEM) capabilities and expertise available at the University of Michigan.

Three sodium borosilicate (from PNNL) and three iron phosphate (from University of Missouri, Rolla) glass waste forms have been studied. For the borosilicate glasses, the onset of $\mathrm{Na}$ migration to nearby regions of the glass was observed under irradiation. As a result, no Na signal is seen in either the electron energy-loss spectroscopy (EELS) or X-ray energy dispersive spectroscopy (EDS) spectra from the irradiation areas under further irradiation. This directly indicates the formation of Na-deplete areas (electron-irradiated area) and Na-rich areas (unirradiated nearby regions). With further increase in the electron doses, another phase separation phenomenon occurred in all three borosilicate glasses. Using energy-filtered transmission electron microscopy (EFTEM), this phenomenon is associated with the separation into borate-rich and silica-rich glass phases. In the Fe-containing borosilicate glasses, the $\mathrm{Fe}$ 
partitions into the borate-rich phase. Further irradiation results in the formation of small Fecontaining crystalline particles. The nature of these Fe-containing crystallites is different for the two Fe-containing glasses, both in lattice parameters and particle sizes for nearly the same dose. This may be attributed to the fact that Fe exists in different valence states in these glasses, and the nature of the valence state changes with irradiation. The results also indicate that reduction of the $\mathrm{Fe}_{2} \mathrm{O}_{3}$ in one glass is occurring, suggesting some decrease in the average Fe valance state. Both the phase separation of the Fe and the change in valance state are consistent with unpublished results obtained after gamma irradiation of these glasses during the first 3-year period of this project. Importantly, the results of this study show that no bubbles formed in any of the Na-borosilicate glasses.

For the iron phosphate glasses, phase segregation occurred in two glasses under irradiation at high electron doses. In contrast, bubbles formed in the third glass, even at a relatively low dose, which may be attributed to Na migration and sublimation. No obvious Fe valence state changes were observed as a result of electron irradiation.

\section{Planned Activities}

At the present time, a renewal proposal regarding this project is pending, and detailed plans for future activities are contained in the proposal. Any actual future activities will depend on whether or not this project receives renewal funding.

\section{Information Access}

William J. Weber, Radiation Effects in Nuclear Waste Materials, Final Report, EMSP Project Number 54672, 2000 (http://emsp.em.doe.gov/products.htm).

B. D. Begg, N. J. Hess, W. J. Weber, R. Devanathan, J. P. Icenhower, S. Thevuthasan, and B. P. McGrail, Heavy-Ion Irradiation Effects on Structures and Acid Dissolution of Pyrochlores, Journal of Nuclear Materials 288 [2-3]: 208-216 (2001).

D. Zhao, L. Li, W. J. Weber, and R. C. Ewing, Gadolinium Borosilicate Glass-Bonded GdSilicate Apatite: A Glass-Ceramic Nuclear Waste Form for Actinides, in Scientific Basis for Nuclear Waste Management XXIV, edited by K. P. Hart and G. R. Lumpkin (Mater. Res. Soc. Symp. Proc. 663, Warrendale, PA, 2001), pp. 199-206.

J. Song, L. R. Corrales, G. Kresse, and H. Jónsson, Migration of Oxygen Vacancies in $\alpha-$ Quartz: The Effects of Excitons and Electron Holes, Physical Review B 64: 134102 (2001).

B. Park, W. J. Weber, and L. R. Corrales, Molecular Dynamics Simulation Study of Threshold Displacements and Defect Formation in Zircon, Physical Review B 64: 174108, 116 (2001).

N. J. Hess, B. D. Begg, S. D. Conradson, D. E. McCready, P. L. Gassman, and W. J. Weber, Spectroscopic Investigations of the Structural Phase Transitions in $\mathbf{G d}_{2}\left(\mathbf{T i}_{1-\mathbf{y}} \mathbf{Z r}_{\mathbf{y}}\right)_{2} \mathbf{O}_{7}$ Pyrochlores, J. Phys. Chem. B 106: $4663-4677$ (2002). 
M. W. A. Stewart, B. D. Begg, E. R. Vance, K. Finnie, H. Li, G. R. Lumpkin, K. L. Smith, W. J. Weber, and S. Thevuthasan, The Replacement of Titanium by Zirconium in Ceramics for Plutonium Immobilization, in Scientific Basis for Nuclear Waste Management XXV, edited by B. P. McGrail and G. A. Cragnolino (Mater. Res. Soc. Symp. Proc. 713, Warrendale, PA, 2002), JJ 2.5, pp. 1-8.

W. J. Weber and R. C. Ewing, Radiation Effects in Crystalline Oxide Host Phases for the Immobilization of Actinides, in Scientific Basis for Nuclear Waste Management XXV, edited by B. P. McGrail and G. A. Cragnolino (Mater. Res. Soc. Symp. Proc. 713, Warrendale, PA, 2002), JJ3.1, pp. 1-12.

J. P. Icenhower, B. P. McGrail, W. J. Weber, B. D. Begg, N. J. Hess, E. A. Rodriguez, J. L. Steele, C. F. Brown, and M. J. O'Hara, Dissolution of $\mathbf{A}_{2} \mathbf{T i}_{2} \mathbf{O}_{7}\left(\mathbf{A}=\mathbf{Y}^{3+}, \mathbf{G d}^{3+}\right.$, or $\left.\mathbf{L u}^{3+}\right)$ Pyrochlore by Experiment at $\mathbf{p H}=2, \mathrm{~T}=90^{\circ} \mathrm{C}$ : Evidence for Solubility Control Using a Linear Free Energy Model, in Scientific Basis for Nuclear Waste Management XXV, edited by B. P. McGrail and G. A. Cragnolino (Mater. Res. Soc. Symp. Proc. 713, Warrendale, PA, 2002), JJ6.2, pp. 1-7.

I. Muller, W. J. Weber, E. R. Vance, G. G. Wicks and D. G. Karraker, Chapter 10: Glass, Ceramics, and Composites, in Advances in Plutonium Chemistry 1967-2000, edited by Darleane Hoffman (American Nuclear Society, La Grange Park, Illinois, 2002), pp. 260-307.

K. L. Smith, Z. Zhang, P. McGlinn, D. Attard, H. Li, G. R. Lumpkin, M. Colella, T. McLeod, Z. Aly, E. Loi, S. Leung, M. Ridgway, W. J. Weber, and S. Thevuthasan, The Effect of Radiation Damage on Zirconolite Dissolution, in Scientific Basis for Nuclear Waste Management XXVI, edited by R. J. Finch and D. B. Bullen (Mater. Res. Soc. Symp. Proc. 757, Warrendale, PA, 2003), in press.

J. P. Icenhower, W. J. Weber, N. J. Hess, S. Thevuthasan, B. D. Begg, B. P. McGrail, E. A. Rodriguez, J. L. Steele, and K. N. Geiszler, Experimental Determination of Dissolution Kinetics of Zr-Substituted Gd-Ti Pyrochlore Ceramics: Influence of Chemistry on Corrosion Resistance, in Scientific Basis for Nuclear Waste Management XXVI, edited by R. J. Finch and D. B. Bullen (Mater. Res. Soc. Symp. Proc. 757, Warrendale, PA, 2003), in press.

William J. Weber (http://emslbios.pnl.gov/id/weber_wj) 